Article

\title{
Determination of Semivolatile Organic Nitrates in Ambient Atmosphere by Gas Chromatography/Electron Ionization-Mass Spectrometry
}

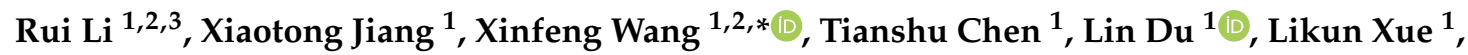 \\ Xinhui Bi ${ }^{2}$, Mingjin Tang ${ }^{2} \mathbb{D}$ and Wenxing Wang ${ }^{1}$ \\ 1 Environment Research Institute, Shandong University, Qingdao 266237, China; lirui@gig.ac.cn (R.L.); \\ xiaotongjiang@mail.sdu.edu.cn (X.J.); tianshu129@163.com (T.C.); lindu@sdu.edu.cn (L.D.); \\ xuelikun@sdu.edu.cn (L.X.); wxwang@sdu.edu.cn (W.W.) \\ 2 State Key Laboratory of Organic Geochemistry and Guangdong Key Laboratory of Environmental \\ Protection and Resources Utilization, Guangzhou Institute of Geochemistry, Chinese Academy of Sciences, \\ Guangzhou 510640, China; bixh@gig.ac.cn (X.B.); mingjintang@gig.ac.cn (M.T.) \\ 3 University of Chinese Academy of Sciences, Beijing 100049, China \\ * Correspondence: xinfengwang@sdu.edu.cn; Tel.: +86-532-58631963
}

Received: 22 January 2019; Accepted: 15 February 2019; Published: 19 February 2019

check for updates

\begin{abstract}
Semivolatile organic nitrates (SVONs) contribute a large proportion of total organic nitrates and play an important role in the tropospheric chemistry. However, the composition and concentrations of SVONs in the atmosphere remain unclear due to the lack of reliable analytical techniques for specific organic nitrates. In this study, a method based on gas chromatography and electron ionization-mass spectrometry was developed to detect ambient SVONs that were collected via polyurethane foam disk enrichment. Three SVONs were identified in the semivolatile samples from urban Jinan during spring based on the characteristic fragment ions of $\left[\mathrm{NO}_{2}\right]^{+}$and $\left[\mathrm{CH}_{2} \mathrm{NO}_{3}\right]^{+}$ and the characteristic fragment loss of $\mathrm{NO}_{2}$ and $\mathrm{NO}_{3}$ : 1-pentyl nitrate (molecular weight $[\mathrm{MW}]=133$ ), 4-hydroxy-isoprene nitrate ( $\mathrm{MW}=147)$, and $(3,4)$-di-hydroxy-isoprene nitrate ( $\mathrm{MW}=163)$. The latter two isoprene nitrates were rarely detected in the real atmosphere in previous studies. The contents of 1-pentyl nitrate, 4-hydroxy-isoprene nitrate, and (3,4)-di-hydroxy-isoprene nitrate were roughly quantified based on the standard of 1-pentyl nitrate, with a detection limit of $50 \mu \mathrm{g} \mathrm{L}^{-1}$. In addition, Fourier transform infrared spectrometry was used to determine the total SVONs content. The average concentrations of 1-pentyl nitrate, 4-hydroxy-isoprene nitrate, (3,4)-di-hydroxy-isoprene nitrate, and total SVONs in Jinan during spring were $20.2 \pm 7.2,13.2 \pm 7.2,36.5 \pm 8.4$, and $380.0 \pm 190.8 \mathrm{ng} \mathrm{m}^{-3}$, respectively. The three identified SVONs contributed only $20.2 \pm 5.5 \%$ to the total SVONs, which suggests that some unidentified SVONs are present in the ambient atmosphere and that studies with improved or advanced analytical techniques will be required to identify them.
\end{abstract}

Keywords: organic nitrates; semivolatile sample; GC/EI-MS; identification; semiquantification

\section{Introduction}

Organic nitrates $\left(\mathrm{RONO}_{2}\right)$ have significant effects on the tropospheric chemistry, air quality, and climate $[1,2]$. They act as a temporary $\mathrm{NO}_{\mathrm{x}}$ reservoir because their relatively long lifespan allows them to be transported to regions far from the original pollution area [3]. The subsequent photo decomposition or thermal decomposition of organic nitrates releases $\mathrm{NO}_{\mathrm{x}}$ back into the atmosphere and exerts further effects on regional nitrogen cycling and $\mathrm{O}_{3}$ production $[4,5]$. Organic nitrates are 
also recognized as important fractions of particles that can exert adverse effects on air quality, visibility, and human health [6-8]. Farmer et al. [9] reported that particulate organic nitrates contributed to $10 \%$ to $19 \%$ of organic matters $(\mathrm{OM})$ during the study of organic aerosols at Riverside. In addition, the presence of the nitrooxy group, hydroxyl group, and carbonyl group increases the hygroscopicity of aerosol, and thus, enhances the activity of cloud condensation nuclei, promotes cloud formation, and affects the climate [3]. The important roles played by organic nitrates in the atmosphere suggest an urgent need to explore the constituents, contents, and transformation mechanisms of such species.

Organic nitrates are generated mainly from the oxidation of volatile organic compounds and are emitted directly from marine sources $\left(C_{1}-C_{2}\right.$ alkyl nitrates) and biomass burning $[2,10]$. The oxidation of alkanes, isoprene, pinene, and limonene by $\mathrm{OH}, \mathrm{NO}_{3}$, and $\mathrm{O}_{3}$ contributes to the majority of total organic nitrates [11-15]. Alkanes are mainly oxidized by $\mathrm{OH}$ and further converted to alkyl nitrates, whereas isoprene, pinene, and limonene are easily oxidized by $\mathrm{OH}, \mathrm{NO}_{3}$, and $\mathrm{O}_{3}$ to produce hydroxyl or multifunctional organic nitrates $[11,12,16,17]$. Alkyl nitrates with a low carbon number $(<5)$ exist mainly in the gas phase. Multifunctional organic nitrates, nevertheless, will be partly distributed in the condensed phase [12]. The moderately volatile organic nitrates, which exist in both particle and gas phases, are known as semivolatile organic nitrates (SVONs), including alkyl nitrates with a moderate carbon number $\left(\mathrm{C}_{5}-\mathrm{C}_{10}\right)$ and isoprene nitrates (first-generation mononitrates) [18]. However, the major constituents and their abundances remain unclear.

In recent years, various techniques, including thermal dissociation laser-induced fluorescence (TD-LIF), Fourier transform infrared spectrometry (FTIR), gas chromatography (GC) or liquid chromatography (LC) followed by mass spectrometry (MS), GC-electron capture detector (GC-ECD), aerosol mass spectrometry (AMS), and the newly developed chemical ionization mass spectrometry (CIMS), have been used to determine the contents of organic nitrates in field observation and laboratory experiments [19-23]. Among them, TD-LIF, FTIR, and AMS can be only used to measure the total contents of organic nitrates based on the signal of the nitrooxy group [14,23-25]. GC-ECD can only be used to measure species with authentic standards, such as low-carbon number alkyl nitrates, peroxyacetyl nitrate, and peroxy propionyl nitrate, which could be synthesized in the laboratory [26-28]. As a result, the previous studies focused mainly on the total contents of organic nitrates in the atmosphere and lacked measurements of the specific components of ambient organic nitrates, especially the SVONs.

GC-MS has been widely used for the determination of organic components due to its combination of superior separation and identification abilities. Because of the relatively high volatility and low polarity of SVONs, GC-MS is a good choice for the detection of individual SVONs. In this study, a method based on GC-MS was developed for the identification and quantification of the SVONs in the atmosphere. Based on the characteristic fragment ions from MS, three SVONs were recognized in the semivolatile samples collected from urban Jinan. Their contents were determined according to the response of the 1-pentyl nitrate standard.

\section{Experiment and Methods}

\subsection{Materials and Reagents}

Polyurethane foam (PUF) disks (diameter, 2.5 inches; thickness, 2.0 inches) were purchased from Tisch Environmental, Inc. (USA). HPLC-grade methanol ( $\geq 99.9 \%)$ and GC-grade hexane $(\geq 98.0 \%)$ were ordered from Sigma-Aldrich (USA) and Aladdin (China), respectively. 3-methyl butyl nitrate (isoamyl nitrate, $>98.0 \%$ ) and 1-pentyl nitrate (amyl nitrate, $>98.0 \%$, GC) were purchased from CNW (Germany) and TCI (Japan), respectively. Isosorbide 5-mononitrate ( $>98 \%)$ and L-carveol $(>97.0 \%)$ were ordered from Energy Chemical (China) and Aladdin (China), respectively. The ultrapure water used in this study was purified with a water purification system (Millipore, USA). 


\subsection{Sample Collection}

The sampling of semivolatile samples was conducted at the Atmospheric Environment Observation Station of Shandong University (AEOS-SDU, $36^{\circ} 40^{\prime} \mathrm{N}, 117^{\circ} 03^{\prime} \mathrm{E}$ ) in urban Jinan, China, as described by Li et al. [29]. The semivolatile organic compounds were collected with a high-volume air sampler (Tisch, New York, NY, USA) with PUF disks. A quartz fiber filter was placed before the PUF disk to remove particulate matters. As a result, the gas-phase and semivolatile compounds passed through the quartz fiber filters and were then absorbed by the PUF disk. Before sampling, the PUF disks were cleaned via sonication in hexane for $60 \mathrm{~min}$ and then in water for $30 \mathrm{~min}$ to remove the organic and inorganic residuals, respectively. They were packaged in clean aluminum foil, dried at $40{ }^{\circ} \mathrm{C}$, and stored at $-20^{\circ} \mathrm{C}$. The semivolatile samples were collected during daytime and nighttime in April, 2016. Both daytime and nighttime samples were collected for 11.5 h (08:00 to 19:30 and 20:00 to 07:30, respectively), with a sampling volume of approximately $140 \mathrm{~m}^{3}$.

\subsection{Sample Preparation}

The semivolatile compounds in the PUF samples were extracted with an orbital shaker. Soxhlet extraction, sonication, and mechanical shaking have been widely used to extract organic compounds [30,31]; however, Soxhlet extraction is not suitable for organic nitrates due to their thermal instability. In addition, sonication may generate $\mathrm{OH}$ radicals, which can result in the degradation of the target species in samples $[30,32,33]$. Therefore, mechanical shaking was selected in this study to extract the semivolatile compounds, including organic nitrates in the PUF disk. The PUF disk was cut into small pieces and soaked in $55 \mathrm{~mL}$ methanol. The soaked PUF sample was subjected to orbital shaking for $2 \mathrm{~h}$ at a constant temperature of $18^{\circ} \mathrm{C}$. The extracted sample solution was then concentrated to approximately $1.2 \mathrm{~mL}$ via rotary evaporation (cold water bath at the temperature of $15^{\circ} \mathrm{C}$ ). After filtration with a $0.22 \mu \mathrm{m}$ pore-size PTFE syringe filter, $20 \mu \mathrm{L}$ of $100-\mathrm{mg} \mathrm{L}^{-1} \mathrm{~L}$-carveol was added into the filtrate. The filtrate was further concentrated to $1 \mathrm{~mL}$ with a gentle high purity nitrogen stream. The final sample solution was stored at $-20^{\circ} \mathrm{C}$ until analysis by GC-MS. In this study, 12 PUF samples were prepared for the analyses of organic nitrates and the extract solution of each PUF sample was injected once into the GC-MS. To examine the recovery rate, $200 \mu \mathrm{L}$ of $100 \mathrm{mg} \mathrm{L}^{-1}$ 3-methyl butyl nitrate was added before mechanical shaking. The average recovery rate of 3-methyl butyl nitrate was $66.8 \% \pm 4.3 \%$ (mean \pm one standard deviation), with the range between $62.9 \%$ and $72.6 \%$.

\subsection{Instrumentation}

\subsubsection{Chromatography Condition}

The Agilent Technologies 7890B GC system coupled with a HP-5MS capillary column (30 $\mathrm{m} \times 0.25 \mathrm{~mm} ; 0.25 \mu \mathrm{m}$ stationary phase thickness) was used for the separation of target species. Helium was used as the carrier gas at a flowrate of $4 \mathrm{~mL} \mathrm{~min}^{-1}$. The oven temperature was programmed as follows: $3 \mathrm{~min}$ at $40^{\circ} \mathrm{C}$, heated at a rate of $10^{\circ} \mathrm{C} \mathrm{min}^{-1}$ to $70^{\circ} \mathrm{C}$ and maintained for $3 \mathrm{~min}$, heated at a rate of $8{ }^{\circ} \mathrm{C} \mathrm{min}^{-1}$ to $110^{\circ} \mathrm{C}$ and maintained for $5 \mathrm{~min}$, and finally heated at a rate of $10^{\circ} \mathrm{C} \mathrm{min}-1$ to $200{ }^{\circ} \mathrm{C}$ and maintained for $12 \mathrm{~min}$. A volume of $1-\mu \mathrm{L}$ sample solution was injected into the injection port with a syringe in splitless mode for the accuracy of quantification. The injector temperature was set as $230^{\circ} \mathrm{C}$ to allow the sample solution to evaporate completely and to prevent thermal decomposition of the target organic nitrates. The time delay of the solvent was 3 min to prevent methanol from getting into the MS detector.

\subsubsection{MS Condition}

The Agilent Technologies 5977B mass selective detector equipped with an electron ionization (EI) source was used to detect SVONs. The ionization energy and the temperature of the EI source were $70 \mathrm{eV}$ and $200^{\circ} \mathrm{C}$, respectively. Under these conditions, molecular ions were completely fragmented into small product ions, and detailed structural information of unknown compounds could be obtained. 
The MS detector continually scanned the mass signals in the full scan mode with a mass $(\mathrm{m} / \mathrm{z})$ range from 5 to $200 \mathrm{amu}$ at a frequency of more than seven times per second. The upper limit of this range was set above the maximum mass of the possible product ions generated from SVONs. The raw data from GC-MS were processed by MassHunter Workstation Qualitative Analysis B.07.00 software (Agilent).

\subsubsection{FTIR Analysis}

In addition, to clarify the proportion of detectable SVONs by GC-MS, FTIR was also used to determine the content of total SVONs (TSVONs). A volume of 30- $\mu \mathrm{L}$ sample extract solution was placed evenly on the $\mathrm{ZnSe}(25 \times 3 \mathrm{~mm})$ window and was detected by FTIR after complete evaporation of the methanol solvent. The nitrooxy group shows three characteristic absorption peaks at $860 \mathrm{~cm}^{-1}$, $1280 \mathrm{~cm}^{-1}$, and 1630 to $1640 \mathrm{~cm}^{-1}$ that correspond to symmetric stretching of NO, symmetric stretching of $\mathrm{NO}_{2}$, and asymmetric stretching of $\mathrm{NO}_{2}$, respectively [12,24,34]. To avoid interference from water vapor and amine functional groups, the absorption peak at $860 \mathrm{~cm}^{-1}$ was used to quantify the content of TSVONs, with isosorbide 5-mononitrate as the standard.

\section{Results and Discussion}

\subsection{Optimization of the GC-MS Method}

The determination method of ambient SVONs in this study was improved and optimized based on the previous studies that focused on the identification of synthetic nitrates mixtures in laboratory and nitrate products in chamber simulation through GC-MS. The chromatography and MS conditions including injector temperature, oven temperature program, injection mode, and MS parameters were further regulated to identify any potential organic nitrates in the semivolatile samples. With consideration of the thermal instability of SVONs, high injector temperature could induce the decomposition of SVONs. Nevertheless, low injector temperature would result in incomplete volatilization of SVONs. Therefore, in this study, the injector temperature was finally set as $230{ }^{\circ} \mathrm{C}$ after various tests to get a high response of the target species in MS. The oven temperature program was also adjusted and the splitless mode was selected to obtain good peak shape and high response, respectively. The mass range was set as 5 to $200 \mathrm{amu}$, which could cover all fragment ions generated from SVONs and prevent interferences from high mass ions. The surrogate standard was chosen as 1-pentyl nitrate for semiquantification of SVONs and then the contents of individual SVONs in the real atmosphere were quantified.

\subsection{Identification of the SVONs}

According to the characteristic fragment ions of organic nitrates, three kinds of SVONs were identified in the semivolatile samples collected from urban Jinan: 1-pentyl nitrate (molecular weight $(\mathrm{MW})=133)$, 4-hydroxy-isoprene nitrate $(\mathrm{MW}=147)$, and $(3,4)$-di-hydroxy-isoprene nitrate $(M W=163)$. Their names follow the naming rules of organic nitrates reported by O'Brien et al. [21] and Xiong et al. [5], and further adjustment was made. Table 1 shows the molecular formulae, retention times, and structures of these three SVONs. 1-pentyl nitrate, 4-hydroxy-isoprene nitrate, and (3,4)-di-hydroxy-isoprene nitrate were eluted at 7.48, 24.83, and $13.77 \mathrm{~min}$, respectively. Small peaks can be observed from the total ion chromatogram of the ambient semivolatile sample (see Figure 1). Because there are no commercially available standards for isoprene nitrates and no corresponding National Institute of Standards and Technology (NIST) standard mass spectra are available, the identification of isoprene nitrates can only be based on the characteristic fragment ions produced by the parent ions. Note that mass spectra of nearly all the chromatogram peaks were examined; however, only three peaks were identified as organic nitrates based on the characteristic fragment ions. 
Table 1. Retention time, molecular formulae, and structures of the three semivolatile organic nitrates (SVONs).

\begin{tabular}{cccc}
\hline Organic Nitrates & Retention Time (min) & Molecular Formula & Structure Formula \\
\hline 1-pentyl nitrate & 7.48 & $\mathrm{C}_{5} \mathrm{H}_{11} \mathrm{NO}_{3}$ & \\
4-hydroxy-isoprene nitrate & 24.83 & $\mathrm{C}_{5} \mathrm{H}_{9} \mathrm{NO}_{4}$ & \\
(3,4)-di-hydroxy-isoprene nitrate & 13.78 & $\mathrm{C}_{5} \mathrm{H}_{9} \mathrm{NO}_{5}$ & \\
\hline
\end{tabular}

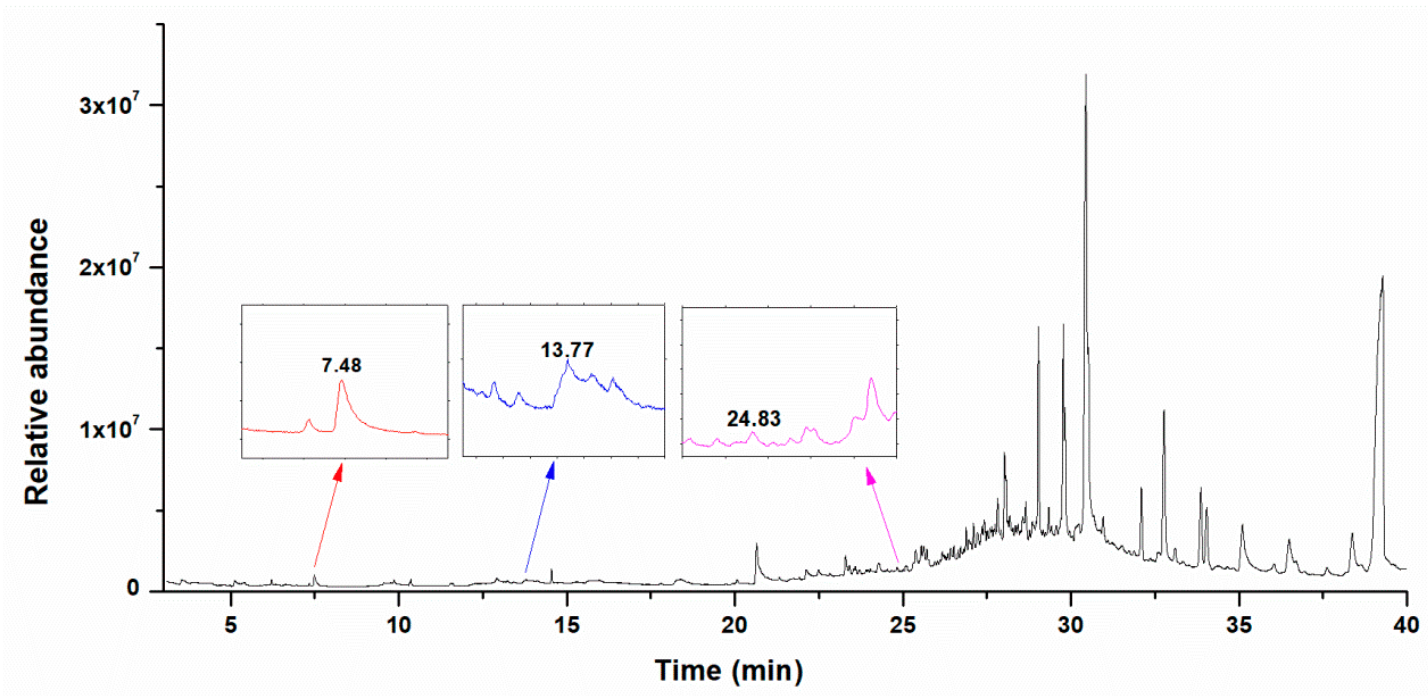

Figure 1. Total ion chromatogram of the semivolatile sample.

\subsubsection{1-Pentyl Nitrate}

Figure 2 shows the mass spectra that corresponded to the peak at $7.48 \mathrm{~min}$. Major product ions of $29,41,43,46,57$, and 76 amu were recognized. An examination of the mass spectra database of NIST suggests that these mass spectra may have come from 1-pentyl nitrate or 3-methyl butyl nitrate. To identify which isomer corresponded to the mass spectra, standard solutions of 1-pentyl nitrate and 3-methyl butyl nitrate were injected into the GC-MS system. The chromatographic peaks of 1-pentyl nitrate and 3-methyl butyl nitrate are shown in Figure 3. Only 1-pentyl nitrate was eluted at $7.48 \mathrm{~min}$. Therefore, the compound eluted at $7.48 \mathrm{~min}$ was identified as 1-pentyl nitrate. As shown in Figure 2, the most intense fragment ion of 41 amu can be explained as $\left[\mathrm{CH}_{3} \mathrm{CH}_{2} \mathrm{C}\right]^{+}$, which is commonly seen from mass spectra with an EI source due to cleavage of carbon chains. The main fragment ions of 46 and 76 amu can be explained as $\left[\mathrm{NO}_{2}\right]^{+}$and $\left[\mathrm{CH}_{2} \mathrm{NO}_{3}\right]^{+}$, respectively. These three ions are characteristic fragment ions of organic nitrates under an EI source condition and can be used to identify other organic nitrates [35]. 


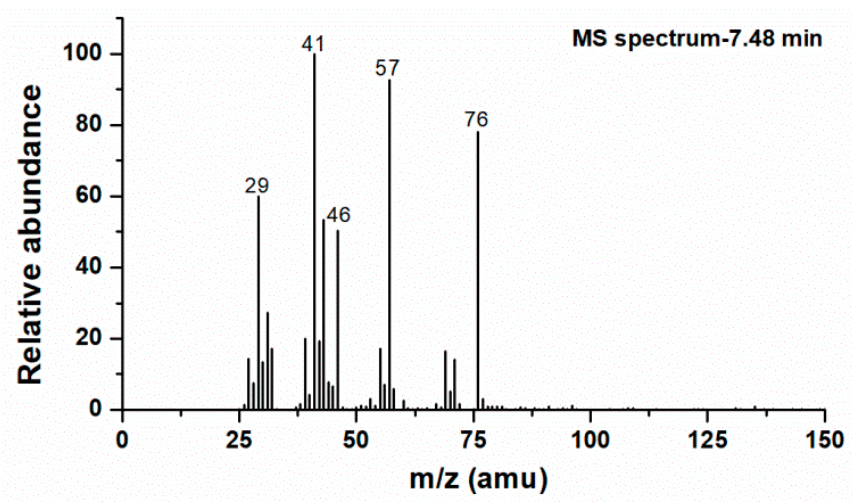

Figure 2. Mass spectra (MS) corresponding to the chromatographic peak at $7.48 \mathrm{~min}$.

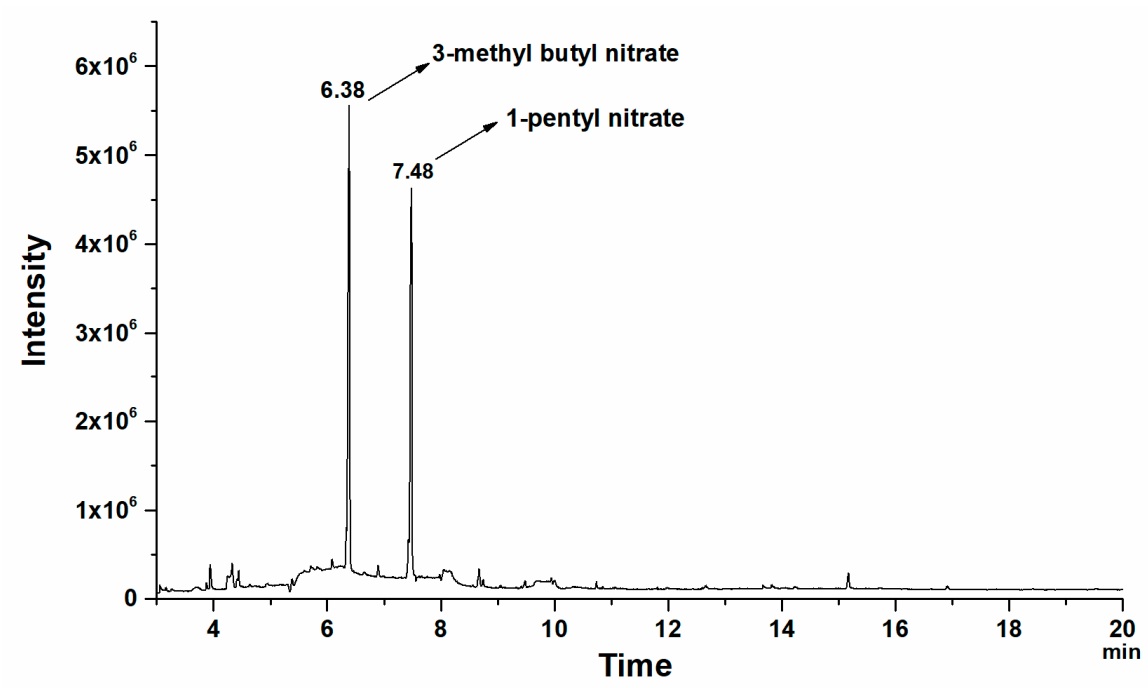

Figure 3. Chromatograms of 1-pentyl nitrate and 3-methyl butyl nitrate.

1-pentyl nitrate is generated mainly from the photochemical oxidation of alkanes in the atmosphere. The isomers of pentyl nitratesm such as 2-pentyl nitrate, 3-pentyl nitrate, and 3-methyl butyl nitrate, have been widely detected in gas-phase samples from around the world [2,27,36,37]. However, 1-pentyl nitrate is rarely observed in the real atmosphere. In one successful case, O'Brien et al. [21] detected 1-pentyl nitrate at a rural site in Ontario, Canada, via GC-ECD coupling with a chemiluminescence detector. In this study, only one chromatographic peak corresponded to 1-pentyl nitrate was observed and no other isomers of pentyl nitrates were detected in the semivolatile samples which may be attributed to the various volatilities of different isomers and the absorptivity of the PUF. The identification of 1-pentyl nitrate in urban Jinan in this study further confirms the existence of 1-pentyl nitrate in gas phase in different atmospheric environments.

\subsubsection{4-Hydroxy-Isoprene Nitrate}

Figure 4 shows the mass spectra that corresponded to the peak at $24.83 \mathrm{~min}$. The major product ions of 41, 46, 55, 57, 71, 83, and 99 amu were obtained. The fragment ions of 46 and 71 amu can be explained as $\left[\mathrm{NO}_{2}\right]^{+}$ions and as product ions generated by the loss of $\left[\mathrm{CH}_{2} \mathrm{NO}_{3}\right](76 \mathrm{amu})$ from the parent ions of $147 \mathrm{amu}$, respectively. No parent ions were obtained due to the intense EI source, as discussed hereinafter. The fragment ions of 57 and 55 amu were most likely generated from further loss of $\left[\mathrm{CH}_{2}\right]$ and $\left[\mathrm{CH}_{3}+\mathrm{H}\right]$, respectively, from the $71 \mathrm{amu}$ ions. The fragment ions at 83 can be explained by the loss of $\left[\mathrm{H}_{2} \mathrm{O}+\mathrm{NO}_{2}\right](64 \mathrm{amu})$ or $\mathrm{NO}_{3}(62 \mathrm{amu})$ followed by two $\mathrm{H}$ atoms from the parent ions. These spectra were similar to those of synthetic Z-(4,1)-IN (i.e., 4-hydroxy-isoprene nitrate) in the laboratory [35]. A small discrepancy was found on the product ions of $99 \mathrm{amu}$, which could be 
explained as the loss of $\mathrm{NO}_{2}(46 \mathrm{amu})$ followed by two $\mathrm{H}$ atoms from the parent ions. Therefore, the compound eluted at 24.83 min was assigned to 4-hydroxy-isoprene nitrate.

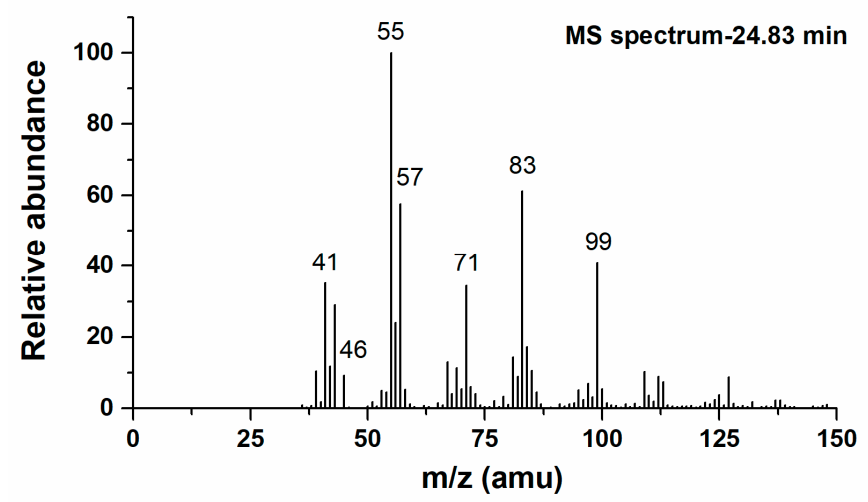

Figure 4. Mass spectra corresponding to the chromatographic peak at $24.83 \mathrm{~min}$.

The 4-hydroxy-isoprene nitrates are produced mainly from the oxidation of isoprene in the presence of oxidants and nitrogen oxides. The common isomers of isoprene hydroxy nitrates include 1-hydroxy-2-nitrooxy isoprene, 2-hydroxy-1-nitrooxy isoprene, 4-hydroxy-3-nitrooxy isoprene, 3-hydroxy-4-nitrooxy isoprene, E/Z-1-hydroxy-4-nitrooxy isoprene, and E/Z-4-hydroxy-1-nitrooxy isoprene. They have been separated and identified by GC-ECD/CIMS or GC-MS in the laboratory from synthetic mixtures of isoprene hydroxy nitrates [5,35,38]. Xiong et al. [5] measured the total concentration of isoprene hydroxy nitrates in the atmosphere in the southeast United States with the CIMS. Vasquez et al. [39] determined two isomers of isoprene hydroxyl nitrates (1,2-IHN and 4,3-IHN) over Pasadena, California using the GC-CIMS. There was rare study which measured the specific constituents of isoprene hydroxyl nitrates in the real atmosphere. This study marks the first time that the 4-hydroxy-isoprene nitrate was detected in the real atmosphere in an urban area.

\subsection{3. (3,4)-Di-Hydroxy-Isoprene Nitrate}

Figure 5 shows the mass spectra that corresponded to the peak at $13.77 \mathrm{~min}$. The major product ions of 41, 57, 73, 88, 101, and 116 amu were obtained. These mass spectra most likely corresponded to $(3,4)$-di-hydroxy-isoprene nitrate or 4-hydroperoxide -isoprene nitrate (i.e., nitrooxyhydroxy diol and nitrooxy hydroperoxide), as reported by Kwan et al. [14]. Detailed product ions information is needed to further identify which isomer corresponds to these mass spectra. The product ions of 101 and 116 amu could be explained by the loss of $\mathrm{NO}_{3}$ and $\mathrm{NO}_{2}$ and one $\mathrm{H}$ atom from the parent ions of 163 (parent ions were not detected), respectively. The loss of $\mathrm{NO}_{3}$ and $\mathrm{NO}_{2}$ was common for organic nitrates and was caused by the relatively low stability of the carbon-oxygen single bond and the oxygen-nitrogen single bond in the $-\mathrm{CONO}_{2}$ group $[19,40]$. The carbon-oxygen single bond and the oxygen-nitrogen single bond both cracked easily under the EI source. The product ions of $73 \mathrm{amu}$ were created from the loss of $\left[\mathrm{CH}_{2} \mathrm{NO}_{3}\right](76 \mathrm{amu})$ and $\left[\mathrm{CH}_{2}\right](14 \mathrm{amu})$ from the parent ions. The product ions of 88 amu can be explained as $\left[\mathrm{CCH}_{2} \mathrm{NO}_{3}\right]^{+}$; however, $\left[\mathrm{CCH}_{2} \mathrm{NO}_{3}\right]^{+}$could be only generated via cleavage of the carbon-carbon double bond and the carbon-carbon single bond between the $\beta$ and $\gamma$ carbon atoms in $(3,4)$-di-hydroxy-isoprene nitrate. Note that the carbon atom connected to the nitrooxy group was called as an $\alpha$ carbon atom. Obviously, the above rule was not suitable for the 4-hydroperoxide isoprene nitrate. Therefore, the possibility that the mass spectra in Figure 5 corresponded to 4-hydroperoxide-isoprene nitrate was ruled out. In addition, the product ions of 41 and 57 amu could be explained by the loss of three $\mathrm{H}$ atoms from $\left[\mathrm{CH}_{2} \mathrm{CHOH}\right]^{+}$and the loss of four $\mathrm{H}$ atoms from $\left[\mathrm{OHCH}_{2} \mathrm{CHOH}^{+}\right.$, respectively. These two ions also corresponded to the structure of $(3,4)$-di-hydroxy-isoprene nitrate; therefore, the compound eluted at 13.78 min was assigned to $(3,4)$-di-hydroxy-isoprene nitrate. 


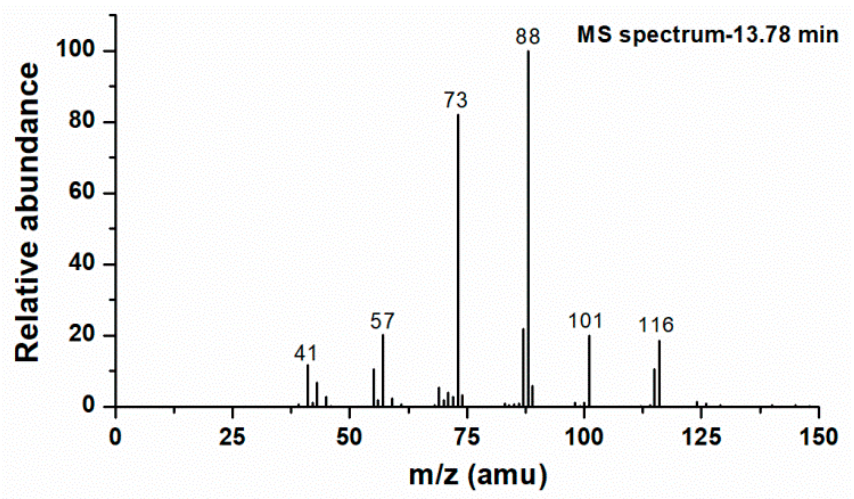

Figure 5. Mass spectra corresponding to the chromatographic peak at $13.78 \mathrm{~min}$.

Similar to 4-hydroxy-isoprene nitrate, (3,4)-di-hydroxy-isoprene nitrate comes from the oxidation of isoprene. This has not previously been observed in the real atmosphere. The previous detection of $(3,4)$-di-hydroxy-isoprene nitrate was achieved via CIMS from the products of isoprene oxidation by $\mathrm{NO}_{3}$ radicals in chamber stimulation experiments by Kwan et al. [14]. In the chamber study, the $(3,4)$-di-hydroxy-isoprene nitrate was detected in particle phase as the isoprene-derived SOA. In our study, this organic nitrate was detected in the semivolatile samples, suggesting that it could partition into both particulate and gas phases. The identification of $(3,4)$-di-hydroxy-isoprene nitrate in semivolatile samples from urban Jinan in this study further indicates the formation and existence of this organic nitrate in the atmosphere.

In this study, the result that only three $C_{5}$ nitrates were identified in semivolatile samples collected in urban Jinan, while no $\mathrm{C}_{6}-\mathrm{C}_{10}$ nitrates were detected, is mainly attributed to two reasons. Firstly, the abundances of $\mathrm{C}_{6}-\mathrm{C}_{10}$ nitrates in the atmosphere are usually lower than those of the low carbon number nitrates $(C \leq 5)$. Various studies have shown that there are abundant $C_{1}-C_{5}$ alkyl nitrates in troposphere and they can even account for $1-2 \%$ of $\mathrm{NO}_{\mathrm{y}}[2,36,41]$. The contents of high carbon number nitrates $(C>5)$ may be lower than the detection limit of this method. Secondly, the high carbon number nitrates, such as pinene nitrates and limonene nitrates $\left(C_{10}\right.$ nitrates $)$, mainly exist in particle phase due to the presences of hydroxy and carbonyl groups. In our previous study, five kinds of $C_{10}$ nitrates were identified in particulate matter samples in urban Jinan [29]. The absence of other $\mathrm{C}_{5}$ nitrates, e.g., 2-pentyl nitrate, 3-pentyl nitrate, and 3-methyl butyl nitrate, in the semivolatile samples detected by GC/EI-MS indicates that there are probably limitations with this sampling method and detection technique.

\subsection{Quantification of SVONs}

Due to the lack of authentic standards, surrogate standards were widely used to quantify the contents of organic nitrates $[18,29,42]$, which is referred to as semiquantification. The surrogate standards were selected based on the similarity of structures and functional groups with the target species to obtain an appropriate response of MS. For the three SVONs of 1-pentyl nitrate, 4-hydroxy-isoprene nitrate, and (3,4)-di-hydroxy-isoprene nitrate, only the authentic standard of 1-pentyl nitrate was available. Because the carbon chain structure and nitrooxy group of 1-pentyl nitrate were similar to those of the other two isoprene nitrates, 1-pentyl nitrate was selected as the surrogate standard for the other two isoprene nitrates for quantification of their concentrations. Based on the ratio of signal to noise timing a factor of 2 [43], the detection limit of GC/EI-MS for 1-pentyl nitrate was estimated to be $50 \mu \mathrm{g} \mathrm{L}^{-1}$, equal to $0.33 \mathrm{ng} \mathrm{m}^{-3}$ in the atmosphere. The most abundant product ions of 1-pentyl nitrate, 4-hydroxy-isoprene nitrate, and (3,4)-di-hydroxy-isoprene nitrate were $\left[\mathrm{CH}_{3} \mathrm{CH}_{2} \mathrm{C}\right]^{+}(41 \mathrm{amu}),\left[\mathrm{CHCH}_{2} \mathrm{OH}\right]^{+}(55 \mathrm{amu})$, and $\left[\mathrm{CCH}_{2} \mathrm{NO}_{3}\right]^{+}(88 \mathrm{amu})$, respectively, which were selected to quantify the contents of the three SVONs. Table 2 lists the contents of the three identified SVONs in semivolatile samples from urban Jinan in spring (recovery rates were considered in the 
quantification of these nitrates). The concentrations of 1-pentyl nitrate, 4-hydroxy-isoprene nitrate, and (3,4)-di-hydroxy-isoprene nitrate in the four detectable semivolatile samples were 20.2 $\pm 7.2,13.2 \pm 7.2$, and $36.5 \pm 8.4 \mathrm{ng} \mathrm{m}^{-3}$, respectively. The total concentration of all three SVONs was $69.9 \pm 15.7 \mathrm{ng} \mathrm{m}^{-3}$. Note that particulate samples collected on filters were also analyzed by GC/EI-MS; however, none of the three SVONs were detected in particulate samples.

Table 2. Concentrations of the three SVONs and their ratios to total SVONs (TSVONs).

\begin{tabular}{cccc}
\hline SVONs & Concentration $\left(\mathbf{n g ~ m}^{-3}\right)$ & Concentration $\left(\mathbf{N ~ n g ~ m}^{-3}\right)$ & ON/TSVON $_{\text {FTIR }}(\mathbf{\%})$ \\
\hline 1-pentyl nitrate & $20.2 \pm 7.2$ & $2.1 \pm 0.8$ & $5.6 \pm 0.6$ \\
4-hydroxy-isoprene nitrate & $13.2 \pm 7.2$ & $1.3 \pm 0.7$ & $1.4 \pm 2.3$ \\
(3, 4)-di-hydroxy-isoprene nitrate & $36.5 \pm 8.4$ & $3.1 \pm 0.7$ & $4.2 \pm 2.8$ \\
Sum & $69.9 \pm 15.7$ & $6.5 \pm 1.5$ & $20.2 \pm 5.5$ \\
TSVONs & $380.0 \pm 190.8$ & $63.4 \pm 70.6$ & \\
\hline
\end{tabular}

Due to the lack of targeted measurements, the abundances of SVONs in the real atmosphere were still not very clear. The three SVONs identified in this study were rarely found in other locations. Particularly, atmospheric concentrations of 4-hydroxy-isoprene nitrate and $(3,4)$-di-hydroxy-isoprene were seldom reported. Fortunately, $\mathrm{O}^{\prime} \mathrm{Brien}$ et al. [21] measured gas-phase 1-pentyl nitrate at a rural site in Ontario on 23 August 1992, with an average concentration of $4.8 \mathrm{ng} \mathrm{m}^{-3}$. In addition, Sun et al. [27] observed the concentrations of gas-phase isomers of 1-pentyl nitrate (i.e., 2-pentyl nitrate, 3-pentyl nitrate, and 3-methyl butyl nitrate) at an urban site in Beijing in the summer of 2008; their data showed average concentrations of $80.2,48.7$, and $102.1 \mathrm{ng} \mathrm{m}^{-3}$, respectively. The average concentration of $20.2 \mathrm{ng} \mathrm{m}^{-3}$ observed for 1-pentyl nitrate in semivolatile samples from urban Jinan during spring is obviously higher than that found in rural Ontario in 1992 and is obviously lower than the concentrations of the isomers of 2-pentyl nitrate, 3-pentyl nitrate, and 3-methyl butyl nitrate found in urban Beijing in the summer of 2008. The variations in the abundance of $C_{5}$-alkyl nitrates were believed to be associated with the mixing ratios of precursors and oxidants and also the gas-particle partitioning (influenced by the season and the meteorological conditions) and were caused partly by the differences in species and measurement methods. Furthermore, Vasquez et al. [39] reported that the average concentrations of 1,2-IHN and 4,3-IHN were 47.0 and $30.2 \mathrm{ng} \mathrm{m}^{-3}$, respectively in Pasadena of California. The contents of two semivolatile isoprene hydroxyl nitrates detected in urban Jinan were close to those of 1,2-IHN and 4,3-IHN in Pasadena.

The concentration of TSVONs can be determined via FTIR. Figure 6 shows the FTIR spectra of methanol solutions of semivolatile sample and isosorbide 5-mononitrate (ISMN) and the standard curve of ISMN is shown in Figure 7. Based on the signal peak at $860 \mathrm{~cm}^{-1}$ from FTIR, the concentration of TSVONs of the samples collected in urban Jinan during spring was $380.0 \pm 190.8 \mathrm{ng} \mathrm{m}^{-3}$ (also included in Table 2). The three identified SVONs contributed only $20.2 \pm 5.5 \%$ of the TSVONs, which indicates that GC-MS via the method in this study failed to identify a very large fraction of the TSVONs, likely because most of the SVONs were thermally unstable and probably decomposed in the GC system. In addition, SVONs with high polarity are not suitable for detection by GC-MS. Further efforts with improved methods or advanced techniques will be required to identify other SVONs. 


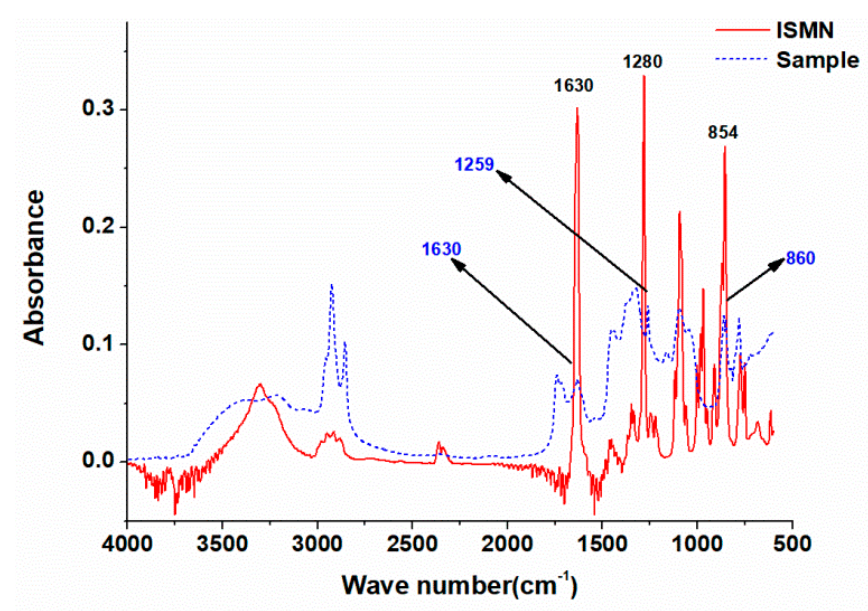

Figure 6. Fourier transform infrared spectrometry (FTIR) spectra of the sample and isosorbide 5-mononitrate (ISMN) standard.

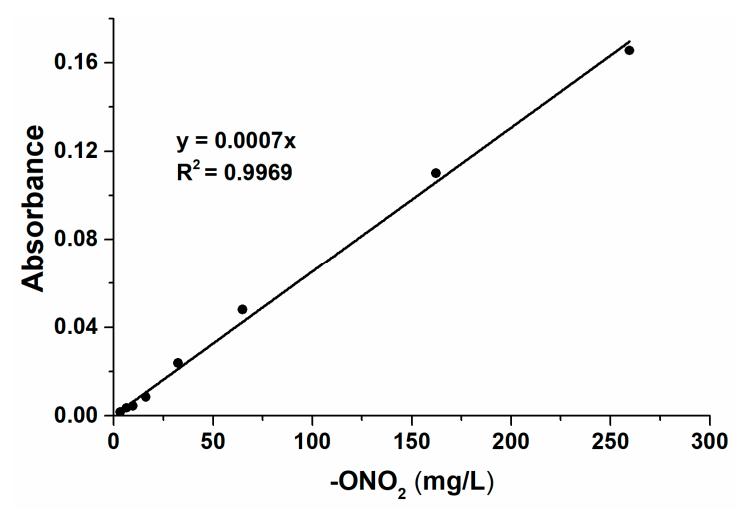

Figure 7. Standard curve of ISMN.

\section{Conclusions}

An analysis method based on GC/EI-MS was developed for the detection of individual SVONs. Based on the characteristic fragment ions of $\left[\mathrm{NO}_{2}\right]^{+}$and $\left[\mathrm{CH}_{2} \mathrm{NO}_{3}\right]^{+}$and the characteristic fragment loss of $\mathrm{NO}_{2}$ and $\mathrm{NO}_{3}$ from the parent ions, together with the available authentic standard and the NIST standard mass spectra, three SVONs were identified in the ambient atmosphere in urban Jinan: 1-pentyl nitrate ( $\mathrm{MW}=133)$, 4-hydroxy-isoprene nitrate ( $\mathrm{MW}=147)$, and $(3,4)$-di-hydroxy-isoprene nitrate $(\mathrm{MW}=163)$. In particular, this is the first study in which 4-hydroxy-isoprene nitrate and $(3,4)$-di-hydroxy-isoprene nitrate have been observed in the real atmosphere, and this study confirms their presence in the atmosphere. The response of 1-pentyl nitrate was used to quantify the contents of these three SVONs, with a detection limit of $50 \mu \mathrm{g} \mathrm{L} \mathrm{L}^{-1}$. The concentrations of 1-pentyl nitrate, 4-hydroxy-isoprene nitrate, and (3,4)-di-hydroxy-isoprene nitrate from GC/EI-MS and TSVONs from FTIR were $20.2 \pm 7.2,13.2 \pm 7.2,36.5 \pm 8.4$, and $380.0 \pm 190.8 \mathrm{ng} \mathrm{m}^{-3}$, respectively. The three SVONs identified contributed only $20.2 \pm 5.5 \%$ to the TSVONs; therefore, most of the SVONs' components remain unknown. Further studies with improved analytic methods and advanced techniques are needed to identify the remaining SVONs.

Author Contributions: Conceptualization, X.W.; methodology, R.L. and X.J.; formal analysis, R.L.; investigation, R.L.; resources, L.D., L.X., X.B., M.T., and W.W.; data curation, R.L., X.J., and T.C.; writing-original draft preparation, R.L.; writing-review and editing, X.W.; supervision, X.W.; funding acquisition, X.W.

Funding: This research was funded by the State Key Laboratory of Organic Geochemistry, GIGCAS, grant number SKLOG-201616. It was also supported by the National Natural Science Foundation of China, grant numbers 41775118, 91644214, 91544213 and the National Key Research and Development Program of China, grant number 2016YFC0200500. 
Conflicts of Interest: The authors declare no conflict of interest.

\section{References}

1. Blake, N.J.; Blake, D.R.; Swanson, A.L.; Atlas, E.; Flocke, F.; Rowland, F.S. Latitudinal, vertical, and seasonal variations of $\mathrm{C} 1-\mathrm{C} 4$ alkyl nitrates in the troposphere over the Pacific Ocean during PEM-Tropics A and B: Oceanic and continental sources. J. Geophys. Res. 2003, 108, 171-181. [CrossRef]

2. Simpson, I.J.; Wang, T.; Guo, H.; Kwok, Y.; Flocke, F.; Atlas, E.; Meinardi, S.; Rowland, F.S.; Blake, D.R. Long-term atmospheric measurements of $\mathrm{C} 1-\mathrm{C} 5$ alkyl nitrates in the Pearl River Delta region of southeast China. Atmos. Environ. 2006, 40,1619-1632. [CrossRef]

3. Renbaum, L.H.; Smith, G.D. Organic nitrate formation in the radical-initiated oxidation of model aerosol particles in the presence of $\mathrm{NO}_{x}$. Phys. Chem. Chem. Phys. 2009, 11, 8040. [CrossRef] [PubMed]

4. Treves, K.; Shragina, L.; Rudich, Y. Henry's law constants of some $\beta-, \gamma_{-}^{-}$, and $\delta$-hydroxy alkyl nitrates of atmospheric interest. Environ. Sci. Technol. 2000, 34, 1197-1203. [CrossRef]

5. Xiong, F.; McAvey, K.M.; Pratt, K.A.; Groff, C.J.; Hostetler, M.A.; Lipton, M.A.; Starn, T.K.; Seeley, J.V.; Bertman, S.B.; Teng, A.; et al. Observation of isoprene hydroxynitrates in the southeastern United States and implications for the fate of NOx. Atmos. Chem. Phys. 2015, 15, 11257-11272. [CrossRef]

6. Ayres, B.R.; Allen, H.M.; Draper, D.C.; Brown, S.C.; Wild, R.J.; Jimenez, J.L.; Day, D.A.; Campuzano-Jost, P.; $\mathrm{Hu}, \mathrm{W}$; de Gouw, J.; et al. Organic nitrate aerosol formation via $\mathrm{NO}_{3}+$ biogenic volatile organic compounds in the southeastern United States. Atmos. Chem. Phys. 2015, 15, 13377-13392. [CrossRef]

7. Mauderly, J.L.; Chow, J.C. Health effects of organic aerosols. Inhal. Toxicol. 2008, 20, 257-288. [CrossRef]

8. Ng, N.L.; Brown, S.S.; Archibald, A.T.; Atlas, E.; Cohen, R.C.; Crowley, J.N.; Day, D.A.; Donahue, N.M.; Fry, J.L.; Fuchs, H.; et al. Nitrate radicals and biogenic volatile organic compounds: Oxidation, mechanisms, and organic aerosol. Atmos. Chem. Phys. 2017, 17, 2103-2162. [CrossRef]

9. Farmer, D.K.; Matsunaga, A.; Docherty, K.S.; Surratt, J.D.; Seinfeld, J.H.; Ziemann, P.J.; Jimenez, J.L. Response of an aerosol mass spectrometer to organonitrates and organosulfates and implications for atmospheric chemistry. Proc. Natl. Acad. Sci. USA 2010, 107, 6670-6675. [CrossRef]

10. Chuck, A.L. Direct evidence for a marine source of C1 and C2 alkyl nitrates. Science (80-) 2002, 297, 1151-1154. [CrossRef]

11. Arey, J.L.; Aschmann, S.M.; Kwok, E.S.C.; Atkinson, R. Alkyl nitrate, hydroxyalkyl nitrate, and hydroxycarbonyl formation from the NOx-air photooxidations of C5-C8 n-alkanes. J. Phys. Chem. A 2001, 105, 1020-1027. [CrossRef]

12. Day, D.A.; Liu, S.; Russell, L.M.; Ziemann, P.J. Organonitrate group concentrations in submicron particles with high nitrate and organic fractions in coastal southern California. Atmos. Environ. 2010, 44, 1970-1979. [CrossRef]

13. Fry, J.L.; Kiendler-Scharr, A.; Rollins, A.W.; Brauers, T.; Brown, S.S.; Dorn, H.-P.; Dubé, W.P.; Fuchs, H.; Mensah, A.; Rohrer, F.; et al. SOA from limonene: Role of $\mathrm{NO}_{3}$ in its generation and degradation. Atmos. Chem. Phys. 2011, 11, 3879-3894. [CrossRef]

14. Kwan, A.J.; Chan, A.W.H.; Ng, N.L.; Kjaergaard, H.G.; Seinfeld, J.H.; Wennberg, P.O. Peroxy radical chemistry and $\mathrm{OH}$ radical production during the $\mathrm{NO}_{3}$-initiated oxidation of isoprene. Atmos. Chem. Phys. 2012, 12, 2259-2302. [CrossRef]

15. Winterhalter, R.; Neeb, P.; Grossmann, D.; Kolloff, A.; Horie, O.; Moortgat, G. Products and mechanism of the gas phase reaction of ozone with $\beta$-pinene. J. Atmos. Chem. 2000, 35, 165-197. [CrossRef]

16. Fry, J.L.; Kiendler-Scharr, A.; Rollins, A.W.; Wooldridge, P.J.; Brown, S.S.; Fuchs, H.; Dubé, W.; Mensah, A.; Maso, M.D.; Tillmann, R.; et al. Organic nitrate and secondary organic aerosol yield from $\mathrm{NO}_{3}$ oxidation of $\beta$-pinene evaluated using a gas-phase kinetics/aerosol partitioning model. Atmos. Chem. Phys. 2009, 9, 1431-1449. [CrossRef]

17. Rosen, R.S.; Wood, E.C.; Wooldridge, P.J.; Thornton, J.A.; Day, D.A.; Küster, W.; Williams, E.J.; Jobson, B.T.; Cohen, R.C. Observations of total alkyl nitrates during Texas Air Quality Study 2000: Implications for $\mathrm{O}_{3}$ and alkyl nitrate photochemistry. J. Geophys. Res. 2004, 109, 7050-7056. [CrossRef]

18. Surratt, J.; Murphy, S.M.; Kroll, J.H.; Ng, N.L.; Hildebrandt, L.; Sorooshian, A.; Szmigielski, R.; Vermeylen, R.; Maenhaut, W.; Claeys, M.; et al. Chemical composition of secondary organic aerosol formed from the photooxidation of isoprene. J. Phys. Chem. A 2006, 110, 9665-9690. [CrossRef] 
19. Docherty, K.S.; Ziemann, P.J. Reaction of oleic acid particles with $\mathrm{NO}_{3}$ radicals: Products, mechanism, and implications for radical-initiated organic aerosol oxidation. J. Phys. Chem. A 2006, 110, 3567-3577. [CrossRef]

20. Ham, W.A.; Herner, J.D.; Green, P.G.; Kleeman, M.J. Size distribution of health-relevant trace elements in airborne particulate matter during a severe winter stagnation event: Implications for epidemiology and inhalation exposure studies. Aerosol. Sci. Technol. 2010, 44, 753-765. [CrossRef]

21. Shepson, P.B.; Muthuramu, K.; Roussel, P.B.; O’Brien, J.M.; Hao, C.; Niki, H.; Hastie, D.R.; Taylor, R. Measurements of alkyl and multifunctional organic nitrates at a rural site in Ontario. J. Geophys. Res. 1995, $100,22795$.

22. Thieser, J.; Schuster, G.; Schuladen, J.; Phillips, G.J.; Reiffs, A.; Parchatka, U.; Pöhler, D.; Lelieveld, J.; Crowley, J.N.; Phillips, G.; et al. A two-channel thermal dissociation cavity ring-down spectrometer for the detection of ambient $\mathrm{NO}_{2}, \mathrm{RO}_{2} \mathrm{NO}_{2}$ and $\mathrm{RONO}_{2}$. Atmos. Meas. Tech. 2016, 9, 553-576. [CrossRef]

23. Xu, L.; Suresh, S.; Guo, H.; Weber, R.J.; Ng, N.L. Aerosol characterization over the southeastern United States using high-resolution aerosol mass spectrometry: Spatial and seasonal variation of aerosol composition and sources with a focus on organic nitrates. Atmos. Chem. Phys. 2015, 15, 7307-7336. [CrossRef]

24. Nielsen, T.; Egeløv, A.H.; Granby, K.; Skov, H. Observations on particulate organic nitrates and unidentified components of NOy. Atmos. Environ. 1995, 29, 1757-1769. [CrossRef]

25. Wooldridge, P.J.; Perring, A.E.; Bertram, T.H.; Flocke, F.M.; Roberts, J.M.; Singh, H.B.; Huey, L.G.; Thornton, J.A.; Wolfe, G.M.; Murphy, J.G.; et al. Total Peroxy Nitrates ( $\Sigma \mathrm{PNs}$ ) in the atmosphere: The Thermal Dissociation-Laser Induced Fluorescence (TD-LIF) technique and comparisons to speciated PAN measurements. Atmos. Meas. Tech. 2010, 3, 593-607. [CrossRef]

26. Liu, L.; Wang, X.; Chen, J.; Xue, L.; Wang, W.; Wen, L.; Li, D.; Chen, T. Understanding unusually high levels of peroxyacetyl nitrate (PAN) in winter in Urban Jinan, China. J. Environ. Sci. 2018, 71, 249-260. [CrossRef] [PubMed]

27. Sun, J.; Li, Z.; Xue, L.; Wang, T.; Wang, X.; Gao, J.; Nie, W.; Simpson, I.J.; Gao, R.; Blake, D.R.; et al. Summertime $\mathrm{C}_{1}-\mathrm{C}_{5}$ alkyl nitrates over Beijing, northern China: Spatial distribution, regional transport, and formation mechanisms. Atmos. Res. 2018, 204, 102-109. [CrossRef]

28. Zhang, J.B.; Xu, Z.; Yang, G.; Wang, B. Peroxyacetyl nitrate (PAN) and peroxypropionyl nitrate (PPN) in urban and suburban atmospheres of Beijing, China. Atmos. Chem. Phys. 2011, 11, 8173-8206. [CrossRef]

29. Li, R.; Wang, X.; Gu, R.; Lu, C.; Zhu, F.; Xue, L.; Xie, H.; Du, L.; Chen, J.; Wang, W.; et al. Identification and semi-quantification of biogenic organic nitrates in ambient particulate matters by UHPLC/ESI-MS. Atmos. Environ. 2018, 176, 140-147. [CrossRef]

30. Mutzel, A.; Rodigast, M.; Iinuma, Y.; Böge, O.; Herrmann, H. An improved method for the quantification of SOA bound peroxides. Atmos. Environ. 2013, 67, 365-369. [CrossRef]

31. Song, Y.; Jing, X.; Fleischmann, S.; Wilke, B.-M. Comparative study of extraction methods for the determination of PAHs from contaminated soils and sediments. Chemosphere 2002, 48, 993-1001. [CrossRef]

32. Miljevic, B.; Hedayat, F.; Stevanovic, S.; Fairfull-Smith, K.E.; Bottle, S.E.; Ristovski, Z.D. To sonicate or not to sonicate PM filters: Reactive oxygen species generation upon ultrasonic irradiation. Aerosol. Sci. Technol. 2014, 48, 1276-1284. [CrossRef]

33. Riesz, P.; Berdahl, D.; Christman, C.L. Free radical generation by ultrasound in aqueous and nonaqueous solutions. Environ. Health Perspect. 1985, 64, 233-252. [CrossRef] [PubMed]

34. Bruns, E.A.; Perraud, V.; Zelenyuk, A.; Ezell, M.J.; Johnson, S.N.; Yu, Y.; Imre, D.; Finlayson-Pitts, B.J.; Alexander, M.L. Comparison of FTIR and particle mass spectrometry for the measurement of particulate organic nitrates. Environ. Sci. Technol. 2010, 44, 1056-1061. [CrossRef] [PubMed]

35. Mills, G.P.; Hiatt-Gipson, G.D.; Bew, S.P.; Reeves, C.E. Measurement of isoprene nitrates by GCMS. Atmos. Meas. Tech. 2016, 9, 4533-4545. [CrossRef]

36. Lyu, X.; Ling, Z.; Guo, H.; Saunders, S.; Lam, S.; Wang, N.; Wang, Y.; Liu, M.; Wang, T. Re-examination of C1-C5 alkyl nitrates in Hong Kong using an observation-based model. Atmos. Environ. 2015, 120, $28-37$. [CrossRef]

37. Simpson, I.J.; Blake, N.J.; Atlas, E.; Flocke, F.; Crawford, J.; Fuelberg, H.E.; Kiley, C.M.; Meinardi, S.; Rowland, F.S. Photochemical production and evolution of selected C2-C5 alkyl nitrates in tropospheric air influenced by Asian outflow. J. Geophys. Res. 2003, 108, 1-29. [CrossRef] 
38. Lockwood, A.L.; Shepson, P.B.; Fiddler, M.N.; Alaghmand, M. Isoprene nitrates: Preparation, separation, identification, yields, and atmospheric chemistry. Atmos. Chem. Phys. 2010, 10, 10625-10651. [CrossRef]

39. Vasquez, K.T.; Allen, H.M.; Crounse, J.D.; Praske, E.; Xu, L.; Noelscher, A.C.; Wennberg, P.O. Low-pressure gas chromatography with chemical ionization mass spectrometry for quantification of multifunctional organic compounds in the atmosphere. Atmos. Meas. Tech. 2018, 11, 6815-6832. [CrossRef]

40. Perraud, V.; Bruns, E.A.; Ezell, M.J.; Johnson, S.N.; Greaves, J.; Finlayson-Pitts, B.J. Identification of organic nitrates in the $\mathrm{NO}_{3}$ radical initiated oxidation of $\alpha$-pinene by atmospheric pressure chemical ionization mass spectrometry. Environ. Sci. Technol. 2010, 44, 5887-5893. [CrossRef]

41. Rattigan, O.V.; Law, K.S.; Clemitshaw, K.C.; Williams, J.; Shallcross, D.E.; Cox, R.A. Gas-phase ultraviolet absorption cross-sections and atmospheric lifetimes of several C2-C5 alkyl nitrates. J. Photochem. Photobiol. A: Chem. 1997, 102, 117-126.

42. He, Q.-F.; Ding, X.; Wang, X.-M.; Yu, J.-Z.; Fu, X.-X.; Liu, T.-Y.; Zhang, Z.; Xue, J.; Chen, D.-H.; Zhong, L.-J.; et al. Organosulfates from pinene and isoprene over the Pearl River Delta, South China: Seasonal variation and implication in formation mechanisms. Environ. Sci. Technol. 2014, 48, 9236-9245. [CrossRef] [PubMed]

43. Sheng, L.; Su, H.; Guo, D. Technologies of Chromatography-Mass Spectrometry; Chemical Industry Press: Beijing, China, 2006.

(C) 2019 by the authors. Licensee MDPI, Basel, Switzerland. This article is an open access article distributed under the terms and conditions of the Creative Commons Attribution (CC BY) license (http://creativecommons.org/licenses/by/4.0/). 